\title{
Significance of Relationship in Multilevel Marketing and its effect on Business Outcome
}

\author{
Dr. Abdul Assis Koroth ${ }^{1}$, Dr. A.K.Sarada ${ }^{2}$ \\ ${ }^{1}$ Associate Professor, Dept of Commerce, Govt. College Madappally. Kerala, India \\ ${ }^{2}$ Professor, DCMS, University of Calicut, India
}

\begin{abstract}
The concept of Multilevel Marketing or network marketing is a method of product distribution. The products are moved through independent distributors. The distributors are given an opportunity to introduce other distributors to the business. Instead of incurring massive media advertising and sales promotion cost, the savings are passed on to distributor consumers. At the same time products are available to consumers at wholesale prices.

However, effective recruiting is essential for the very existence of the majority of direct selling companies including multilevel marketing organisations since the survival of these organisations depend on the ability to make more and more new recruits to replace those who have discontinued. MLM distributors can have a relationship with both their "upline" sponsor and their "downline" recruits. They also often work cooperatively by holding common recruitment meetings and sales training sessions. Distributors of multilevel marketing companies foster a combination of friendship and instrumentality in developing networks.

This paper describes the problems and sets out a research paradigm to investigate the influence of relationship in building network which is a prerequisite for the better performance of distributors in multilevel marketing in Kerala's environment.
\end{abstract}

Keywords: Downline. Multilevel Marketing, Network, Relationship, Upline.

\section{Introduction}

Multi Level Marketing (MLM) is gaining much attention in business circles recently. In order to eliminate the defects associated with the present system of marketing as regards to distribution channel, promotion and advertising; there is a need for a new strategy in marketing. Direct selling is an innovative version of the direct channel system.

The concept of Multilevel Marketing or referral marketing is a method of product distribution. The products are moved through independent distributors. The distributors are given an opportunity to introduce other distributors to the business. Instead of incurring massive media advertising and sales promotion cost, the savings are passed on to distributor consumers. Distributors share the large revenue that normally goes to the middleman. At the same time products are available to consumers at wholesale prices.

However, effective recruiting is very essential for the very existence of the majority of direct selling companies including multilevel marketing organisations because the survival of these organisations depend on the ability to make more and more new recruits to replace those who have discontinued. MLM distributors can have a relationship with both their "upline" sponsor and their "downline" recruits. They also often work cooperatively by holding common recruitment meetings and sales training sessions. Distributors of multilevel marketing companies foster a combination of friendship and instrumentality in developing networks.

This paper describes the problems and sets out a research paradigm to investigate the influence of relationship in building network which is a prerequisite for the better performance of distributors in multilevel marketing in Kerala's environment.

For the purpose of the study, relationships can be defined as those with the emotional attachment and/or intimacy existing among relatives and friends. By relatives here mean closely related persons like siblings, parents, in - laws, cousins, nieces and such others. By 'friends' the researchers mean those persons who are dependable, trustworthy and loyal. All others, other than friends and relatives are grouped under the category of colleagues.

\section{Review of Literature}

The role of the recruiter in direct selling is similar to that of a supervisor or sales manager in a typical selling situation. In conventional selling the sales manager is responsible for the recruitment, training and development of the sales force and, in return, receives a salary plus a bonus that is dependent on the level of sales or product volume achieved by the team.

In direct selling, although the role is of a more informal nature, the recruiter assumes the role of a mentor, taking the new recruit under their wing and teaching them the fundamentals of the business: how direct selling 
operates; how to run the business; how to sell the product or service; product knowledge and use, and effective recruiting techniques. Effective recruiting is essential for the very existence of the majority of direct selling companies because the survival of the organisation is dependent on the ability to continually make new recruits to replace those who have left, or to build the downline. The recruiting of new distributors in direct selling is an economic imperative particularly in party-plan and multilevel organisations.

In the early stages of a distributorship the relationship between recruiter and recruit is especially close: the recruiter has a personal interest in the new recruit doing well as their position in the organisation and their income increases as the size of their 'team' increases. In this period of new skill and knowledge acquisition the need for support is higher than at later stages when confidence is increased, and the new recruit is initially heavily dependent on the sponsor for support and encouragement in this transition phase. This level of support has been shown to significantly increase satisfaction in a retail environment.

Direct selling involves selling consumer goods to private people in contexts in which retail selling does not usually occur, such as in homes and workplaces (Berry 1997, p. 21). Network marketing companies are a special type of direct selling organization because their agents can generate income in two ways. They can earn commissions and retail profits by selling directly to retail customers, and they can recruit and manage their own network of sales agents (on whose sales they earn a commission).Those who undertake this second incomegenerating activity are often called "sponsors " who develop a "downline" of sales agents. Therefore, network marketing agents can have a relationship with both their "upline" sponsor and their "downline" recruits. They also often work cooperatively by holding common recruitment meetings and sales training sessions. Network marketing agents are well suited for this study because the organizations they work for encourage them to use existing social networks as a pool for recruiting new agents encourage people to develop a list of potential sales contacts by creating a "warm list" of people who know them by name (Bremner 1996; Carmichael 1993; Clothier 1994; Poe 1995).

As a result, network marketing agents are often sponsored and supervised by someone who is at least a social acquaintance and sometimes also a friend. In other words, as part of their job, network marketing agents are encouraged to introduce business role expectations into friendships (Lan 2002; Pratt and Rosa 2003).Therefore, they face potential role conflict.

Furthermore, research on network marketing has demonstrated that despite this advice and encouragement, not all network marketing agents pursue a business strategy that relies primarily on an existing social network for customers. For several reasons, including concerns about upsetting friends and acquaintances, some agents instead decide "that the effort and potential social cost associated with selling to friends are too high" (Grayson 1996) and that "strangers or remote friends are "better 'targets than close friends because distributors feel less pressure' (Lan 2002). Therefore, as Merrilees and Miller (1999) illustrate in their study of network marketing sales strategies, some agents deliberately focus their selling and recruiting efforts on people who are not friends. Nonetheless, when non friends join a downline, their upline sponsor may then be interested in building a close personal relationship with them. According to Lan (2002, p.177), some sponsors actively "transform their relations with fellow distributors" by developing particularly close relationships with them. As one of Pratt's (2000) Amway informants explained, if you "build a friendship, you build a directship" (a "directship" is achieved when an agent's downline exceeds specific sales targets). Similarly, several informants reported that partly because sponsors pay such intense personal attention to recruits, they often naturally become friends (Grayson 1996). Thus, network marketing sometimes involves imposing a business role on a friendship and sometimes involves developing a friendship role within a business relationship.

Network marketing companies are not the only organizations whose tactics can foster a combination of friendship and instrumentality. Employees in other sectors are also encouraged to "treat customers like best friends" (Geller 2006) or to "make a friend —not a transaction" (Tan and Steinberg 2007). Furthermore, across a range of industries, companies frequently try to capitalize on social relationships to achieve commercial aims.

Some encourage their salespeople to use their friends and family networks to generate new business leads (Broker 2005; Huisken 2005; Meagher 2006), and others, including companies as large as Sony, Gap, and Citibank, offer customers financial incentives for referring friends and family (Bulik 2006; Mitchell 2003;).

\section{Statement of the Problem}

Effective recruiting is indispensable for the very existence of multilevel marketing organisations which in turn built up on relationships. MLM distributors can have a relationship with both their "upline" sponsor and their "downline" recruits. Upline distributors encourage their salespeople to use their friends and family networks to generate new business achievements. Relationship plays an important role in developing network in multilevel marketing system. Therefore it is quite reasonable to examine the influence of relationships in building network and consequently its reflection in business outcomes. 


\section{Objectives of the Study}

The study is conducted to examine the involvement of distributors in MLM practices, and how the involvement is adding value to their business and to assess the influence of relationship in developing MLM networks and its effect on business outcomes.

\section{Research Methodology}

The survey research design method was used for the study. The present study is based on both primary and secondary data. The empirical data for this study was obtained through a survey conducted among the distributors of sample companies. It involves using a self designed questionnaire in collecting data from the respondents. Population of this research is defined to be the adults over 18 years residing in three regions of Kerala who have enrolled as distributors of any of these MLM companies whether they are active or inactive. The sample used in this study consists of 614 distributors cum customers. Convenience sampling was used for primary data collection. The whole state of Kerala is divided into three strata based on the geographical locations namely the southern Kerala, central Kerala and the north Kerala. Questionnaires were given to all participants irrespective of their demographic features. Thus participation of distributors from all walks of life was ensured. The questionnaire was pretested using a convenience sample of 25 distributors. The final questionnaire was prepared using a pilot study.

\section{Hypotheses of the Study}

The nature of this research study was quantitative. A questionnaire was designed whose purpose was to prove or disprove a number of working hypotheses. The principal hypotheses, which were considered in this research study, are outlined below.

1. The source of introduction does not differ significantly with the length of experience.

2. There is no significant relation between the reason for joining and the source of introduction.

3. There is no significant relation between the experience of the distributors and the people whom they contacted for enrolment.

4. Distributors' with strong feelings of relationship toward their business partners would produce better business outcomes than distributors with weak feelings of relationship.

\section{Data Analysis}

Various statistical tools were used for analysing data gathered through the administration of the questionnaire.

\section{Results and Discussion}

The first part of the analysis shows the demographic characteristics of the respondents. This is followed by a question-by-question analysis of the results of the study.

Table -1

Demographic Features of Multilevel Marketing Distributors

\begin{tabular}{|l|l|c|c|}
\hline \multicolumn{1}{|c|}{ Variable } & Response Categories & n & \% \\
\hline Gender & Male & 518 & 84 \\
& Female & 96 & 16 \\
\hline Age Group & $18-30$ & 197 & 32 \\
& $30-40$ & 278 & 45 \\
& Above- 40 & 139 & 23 \\
\hline Marital status & Married & 393 & 64 \\
& Unmarried & 221 & 36 \\
\hline Place of residence & Urban & 325 & 53 \\
& Semi-urban & 167 & 27 \\
& Rural & 122 & 20 \\
\hline Education & SSLC & 268 & 44 \\
& HSC & 134 & 22 \\
& Graduation & 82 & 21 \\
& Others & 257 & 13 \\
\hline Employment & Govt. or Private & 119 & 19 \\
& Business or profession & 238 & 39 \\
\hline
\end{tabular}

Source: Survey Data 


\section{Distributors Involvement in MLM Business}

Greater involvement on the part of distributors is essential for success in any kind of business. A distributor can take up MLM either as full time job or as a part time job. A distributor who involved in MLM as a full time distributor is likely to succeed in the business than his part-time counterpart. With this end, all of the respondents were asked whether they have enrolled as a distributor full time or part time basis. The data gathered on this question is exhibited in table 2.

There were several answers possible. Table 2 reveals that a majority of the respondents $(88 \%)$ had joined in multilevel marketing as a part time basis. Only $12 \%$ of the distributors have taken up multilevel marketing as means of full time employment. For most people MLM is a supplement source of income indicating that they have other responsibility and can only commit themselves on a part time basis.

Table 2

Nature of Involvement of MLM Distributors

\begin{tabular}{|c|c|c|c|}
\hline \multirow{2}{*}{ Region } & \multicolumn{3}{|c|}{ Types of MLM Distributor } \\
\cline { 2 - 4 } & Part time & Full Time & Total \\
\hline South & $158(90)$ & $18(10)$ & 176 \\
\hline Central & $146(90)$ & $17(10)$ & 163 \\
\hline North & $238(86)$ & $37(14)$ & 275 \\
\hline Total & $552(88)$ & $72(12)$ & 614 \\
\hline
\end{tabular}

Source: Survey Data

Note: Figures in parenthesis indicate percentage to total

\section{i) Length of Experience}

The respondents were asked the length of experience in multilevel marketing. Their responses are summarised in table 3 .

Table 3

Length of Experience in Multilevel Marketing

\begin{tabular}{|c|c|c|c|}
\hline Length of Experience & No. of Respondents & Percentage & $\begin{array}{c}\text { Cumulative } \\
\text { Percentage }\end{array}$ \\
\hline Less than 2 years & 404 & 65.79 & 65.79 \\
\hline Between 2-5 years & 164 & 26.71 & 92.50 \\
\hline More than 5 years & 46 & 7.50 & 100 \\
\hline
\end{tabular}

Source: Survey Data

Of those surveyed, 404 respondents, that is, 65.79 found to be involved in MLM business for a period of less than 2 years. 26.71 percent of respondents are involved for a period between 2 to 5 years. Only a 7.5 percent of the respondents had an experience of more than 5 years in this business. From this figure it is clear that most of the respondents are new recruits

\section{ii) Relationship between Educational qualification and Length of Experience}

The analysis of the information contained in table 4 obtained as a result of the cross-tabulation run between educational qualification and length of experience.

Table 4

Educational Qualification and Length of Experience

\begin{tabular}{|c|c|c|c|c|c|}
\hline \multirow{2}{*}{ Length of Experience } & \multicolumn{5}{|c|}{ Educational Qualification (in percentages) } \\
\cline { 2 - 6 } & $\begin{array}{c}\text { S.S.L.C or } \\
\text { below }\end{array}$ & $\begin{array}{c}\text { Higher } \\
\text { Secondary }\end{array}$ & College & Other & Total \\
\hline Less than 2 years & 69.45 & 59.76 & 54.41 & 61.59 & 62.30 \\
\hline Between 2-5 years & 28.67 & 44.26 & 40.64 & 34.20 & 33.44 \\
\hline More than 5 years & 1.88 & 2.02 & 4.95 & 4.21 & 4.26 \\
\hline Total & 100 & 100 & 100 & 100 & 100 \\
\hline
\end{tabular}

Source: Survey Data

It has been observed that members having post secondary educational degree are people who are taking the business seriously and staying in for a period of five years or more. The statistics pertaining to the respondent's relationship between education and length of experience is summarised in table 5 .

Information given in table 5 shows a very low degree of positive relationship between the length of experience and the educational qualifications of respondents. In fact the relationship is found to be insignificant. 
Relationship between variables is significant when the value is less than .05 , justifying the earlier preposition that anyone or everyone above 18 years of age with sound mind can become member/ distributor in multilevel marketing schemes with no requirement for qualifications or previous experience. This yet may be another reason for MLM to gain popularity among people having low level of education.

Table 5

Correlation between Education and Length of Experience

\begin{tabular}{|c|c|c|c|}
\hline & & $\begin{array}{c}\text { Educational } \\
\text { Qualifications }\end{array}$ & $\begin{array}{c}\text { Length of } \\
\text { Experience }\end{array}$ \\
\hline \multirow{2}{*}{ Educational Qualifications } & Correlation & 1 & 0.046 \\
\cline { 2 - 4 } & Sig. (2 tailed) & - & 0.521 \\
\hline \multirow{2}{*}{ Length of Experience } & Correlation & 0.046 & 1 \\
\cline { 2 - 4 } & Sig. (2 tailed) & 0.521 &.- \\
\hline
\end{tabular}

\section{iii) Educational qualification and nature of involvement}

Members are undertaking MLM practices either part-time or full time. Thus the researcher has tried to correlate educational practices with the nature of involvement. The correlation analysis does show relationship (presented in table 6), which is however insignificant as the significance value is .064 greater than .05 .

Table 6

Correlation between Education and Nature of Involvement

\begin{tabular}{|c|c|c|c|}
\hline \multirow{2}{*}{ Educational Qualifications } & Correlation & $\begin{array}{c}\text { Educational } \\
\text { Qualifications }\end{array}$ & $\begin{array}{c}\text { Length of } \\
\text { Experience }\end{array}$ \\
\cline { 2 - 4 } & Sig. (2 tailed) & 1 & 0.089 \\
\hline \multirow{2}{*}{ Part time /Full time } & Correlation & - & 0.069 \\
\cline { 2 - 4 } & Sig. (2 tailed) & 0.064 & 1 \\
\hline
\end{tabular}

The cause of insignificance can easily be identified by analyzing cross tabulation between educational qualification and nature of involvement by respondents (Table 7). No particular trend can be ascertained except for the fact that people with graduate degree is more involved in the practices either part time or full time.

Table 7

Educational Qualification and Nature of Involvement

\begin{tabular}{|l|c|c|c|}
\hline Educational Qualification & Part Time & Full Time & Total \\
\hline S.S.L.C or below & 19.27 & 15.28 & 17.27 \\
\hline Higher Secondary & 18.63 & 21.26 & 19.65 \\
\hline College & 51.86 & 42.02 & 54.14 \\
\hline Other & 10.24 & 21.44 & 8.94 \\
\hline Total & 100 & 100 & 100 \\
\hline
\end{tabular}

\section{Role of Relationship in MLM}

Relationship plays an important role in developing network in multilevel marketing system. It is not surprising that much empirical work on relationship in marketing has found that friends and relatives are more likely to be valuable exchange partners; that is, they exhibit characteristics that are likely to influence the bottom line positively. Although relationship may have a positive effect on business outcomes, the main purpose of this study is to explore whether this effect is moderated downward by a conflict between friendship role and business role expectations. Distributors often are encouraged to consider their friends and relatives potential customers.

All of the respondents were also asked who influenced them to join as a distributor in multilevel marketing. There were several answers possible. The resultant data is depicted in table 8 .

The table 8 indicates that majority of the respondents $(68 \%)$ joined in multilevel marketing under the influence of friends and relatives followed by colleagues and upline leaders. Thus it is seen that these respondents are 
joined under the influence of others especially from friends and relatives who used personal relationships to enrol new distributors.

In order to examine this, a further analysis is made by asking the respondents that whether they were joined in multilevel marketing under their own will or due to the pressure of others. Only $3 \%$ of the respondents have joined in multilevel marketing under their own will. A majority of the respondents joined in the scheme simply due to the heavy pressure from others.

Table 8

People Who Influenced To Join MLM

\begin{tabular}{|l|c|c|}
\hline Influential Factor & No. of Respondents & Percentage \\
\hline Friends & 238 & 39 \\
\hline Relatives & 176 & 29 \\
\hline Colleagues & 86 & 14 \\
\hline Upline Leaders & 114 & 18 \\
\hline Total & 614 & 100 \\
\hline
\end{tabular}

Source: Survey Data

\section{i ) Sources of Introduction to MLM and Length of Experience}

All of the respondents were also asked who influenced them to join as a distributor in multilevel marketing. There were several answers possible. The resultant data along with the experience of the distributors in multilevel marketing field is depicted in table 9 .

Table 9

Sources of Introduction and Length of Experience

\begin{tabular}{|l|c|c|c|c|c|}
\hline \multirow{2}{*}{ Length of Experience } & \multicolumn{5}{|c|}{ Sources of Introduction } \\
\cline { 2 - 6 } & Friends & Relatives & Colleagues & Others & Total \\
\hline Less than 2 year & 152 & 122 & 44 & 86 & 404 \\
\hline Between 2-5 years & 69 & 43 & 32 & 20 & 164 \\
\hline More than 5 years & 17 & 11 & 10 & 8 & 46 \\
\hline$\quad$ Total & 238 & 176 & 86 & 114 & 614 \\
\hline
\end{tabular}

The data in the table 9 clearly shows that majority of the distributors were introduced by their friends and relatives. The researcher tested whether there is any significant difference between length of experience in the field of multilevel marketing and their sources of introduction.

This aspect was further statically tested with the help of $\mathrm{F}$ test. The test was applied at $5 \%$ significance level with the hypothesis that the source of introduction does not differ significantly with the length of experience. The calculated value of $\mathrm{F}$ for the source of introduction of respondents is 2.36 . But, the critical value of $\mathrm{F}$ is 4.75 . The calculated value being less, the difference in the opinion of distributors regarding source of introduction to MLM is insignificant. Therefore it is concluded that the respondents' have the same opinion regarding the source of introduction to MLM.

Further, the calculated value of $\mathrm{F}$ for the length of experience is -26.23 . But, from the $5 \% \mathrm{~F}$ table, its critical value for $\mathrm{v} 2=2$ and $\mathrm{v} 3=6$ appears to be 5.14 . The calculated value being less than the critical value the difference in the opinion of distributors regarding the source of introduction to MLM in terms of length of the distributors experience is also insignificant. Therefore it is concluded that the respondents have the same opinion regarding sources of introduction to MLM even in terms of the length of experience.

\section{ii) Reason for Joining MLM}

In addition to the above, respondents were also asked what really prompted them to join as a distributor in network marketing. The result obtained from the survey is demonstrated in table 10.

The results in Table 10 found that $62 \%$ of respondents had joined as a distributor as a result of continuous pressure from existing distributors. The remaining distributors were motivated by other reasons such as intention to use good quality products and of which only $15 \%$ of the respondents was taken up the multilevel marketing system as a means of employment.

Thus, from the analysis it is clear that the prime motive behind joining in MLM was not to earn additional income or use quality products, but due to continuous pressure from existing distributors. 
Table 10

Reason for Joining MLM

\begin{tabular}{|l|c|c|}
\hline Reason for Joining & No. of Respondents & Percentage \\
\hline To earn additional income & 92 & 15 \\
\hline To use quality products at reasonable rates & 144 & 23 \\
\hline Pressure from existing distributors & 378 & 62 \\
\hline Total & 614 & 100 \\
\hline
\end{tabular}

Source: Survey Data

\section{iii) Role of friends and relatives to join MLM}

The above analysis indicates that majority of distributors' joined MLM system due to heavy pressure from existing distributors. A lion share of existing distributors includes friends, relatives and colleagues. Therefore, the study also examined what role played by the friends and relatives in persuading the new distributors to join multilevel marketing business. The details of the above data are shown in table 11.

Table 11

Sources of Introduction and Reason to Join MLM

\begin{tabular}{|c|c|c|c|c|c|}
\hline \multirow[t]{2}{*}{ Reason for Joining } & \multicolumn{5}{|c|}{ Sources of Introduction } \\
\hline & Friends & Relatives & Colleagues & Others & Total \\
\hline Earn additional income & 42 & 23 & 15 & 12 & 92 \\
\hline Use quality products & 68 & 46 & 17 & 13 & 144 \\
\hline Pressure from distributors & 128 & 107 & 54 & 89 & 378 \\
\hline Total & 238 & 176 & 86 & 114 & 614 \\
\hline
\end{tabular}

Source: Survey Data

This phenomenon is examined with the help of chi-square test. The test was applied at 5\% significance level with the following hypothesis. Chi -square value $=21.59$. Critical Value at for 8 degree of freedom $5 \%$ significance level $=12.59$. The hypothesis is rejected. Therefore it is concluded that there is a significant relation between the reason for joining and the source of introduction to MLM. Thus it is clear that majority of the distributors had joined to MLM due to heavy pressure from their friends, relatives and colleagues.

iv) Exploitation of Relationship

Multilevel marketing has been built up on relationship. It is obvious from the previous analysis that the main sources of recruitment for a distributor were friends, relatives and colleagues. Therefore as a continuation of the previous analysis, it is necessary to examine whether the relationship is exploited by the distributors for the purpose of selling the products and recruiting new downlines.

The table 12 given below exhibits various types of people the distributors had contacted for enrolling as new recruits into the MLM business as their downlines along with the length of experience.

\section{Table 12}

Exploitation of Relationship in MLM

\begin{tabular}{|l|c|c|c|c|c|}
\hline \multirow{2}{*}{ Length of Experience } & \multicolumn{2}{|c|}{ People Contacted for Enrolment } \\
\cline { 2 - 6 } & Friends & Relatives & Colleagues & Others & Total \\
\hline Less than 2 year & $133(33)$ & $147(36)$ & $53(13)$ & $71(18)$ & 404 \\
\hline Between 2-5 years & $58(35)$ & $42(26)$ & $43(26)$ & $21(13)$ & 164 \\
\hline More than 5 years & $11(24)$ & $7(15)$ & $21(46)$ & $7(15)$ & 46 \\
\hline Total & $202(33)$ & $196(32)$ & $117(19)$ & $99(16)$ & 614 \\
\hline
\end{tabular}

Source: Survey Data

Note: Figures in parenthesis indicate percentage to tota

The table 12 clearly reveals that about 84 percent of the respondents contacted their friends, relatives and colleagues for the purpose of enrolling them as distributors of MLM. The table further shows that those distributors who are having less than two year experience mainly contacted their relatives for the purpose of enrolment. On the other hand, distributors having experience between two to five years experience mainly contacted friends for enrolment and those distributors having more than five years experience approached their colleagues to expand the network. This indicates one of the most crucial aspects of multilevel marketing that is many of the existing distributors would like to capitalize the relationship to build up their network.

This aspect is further examined with the help of chi-square test. The test was applied at $5 \%$ significance level with the following hypothesis. Chi -square value $=40.6593$. Critical Value at for 8 degree of freedom $5 \%$ significance level $=12.59$. The hypothesis is rejected. Therefore it is concluded that there is a significant relation between the experience of the distributors and the people whom they contacted for enrolment. 


\section{v) Types of Relationship}

Multilevel marketing distributors can have relationship with both their upline sponsor and members of their downline. Therefore, the survey for this study measured two types of multilevel marketing relationships: relationships between respondents and their upline sponsors and friendships between respondents and members of their downline.

Thus, analysis is made and tested from two perspectives. One focused on individual relationships in which each respondent is the supervisee, and one focused on a set of downline relationships in which each respondent is the supervisor. To the extent that the results for one kind of relationship are replicated in the results for the other kind, this suggests a robust effect that occurs regardless of whether the relationship is with a supervisor or a supervisee.

To assess the level of relationship that respondents felt for their upline sponsor, four survey items were used, each of which focused on one of the four relationship characteristics identified namely intimate selfdisclosure, voluntary social interaction, exchange orientation, and intrinsic orientation. Respondents rated the four items comparably, so each person's ratings on all four items were averaged to produce a measure of relationship strength. Respondents who score four or more was treated to show 'Strong relationship' and those who scored less than four was treated to show 'weak relationship' with their sponsors. Under these background four relationship characteristics namely intimacy, voluntary social interaction, exchange orientation, and intrinsic orientation were measured and the result thereof is shown in table 13.

\section{Table 13}

Relationship Strength with Sponsors

\begin{tabular}{|l|c|c|c|}
\hline \multirow{2}{*}{ Relationship Characteristics } & \multicolumn{3}{|c|}{ Relationship Strength } \\
\cline { 2 - 4 } & Strong & Weak & Total \\
\hline Intimacy & 186 & 63 & 249 \\
\hline Voluntary Social Interaction & 74 & 61 & 135 \\
\hline Exchange Orientation & 64 & 24 & 88 \\
\hline Intrinsic Orientation & 112 & 30 & 142 \\
\hline Total & $436(71)$ & $178(29)$ & 614 \\
\hline
\end{tabular}

Source: Survey Data

Note: Figures in parenthesis indicate percentage to total

The table 13 shows that out of total 614 respondents, $71 \%$ shows strong relationship with their sponsors and $21 \%$ of the respondents, on the other hand, shows weak relationship with the sponsors. This again reveals the fact that the very foundation of MLM and the management of network is built up on relationships.. Respondents were also asked to indicate the number of friends or relatives in their "indirect downline," which is a multilevel marketing term that refers to downline members who were sponsored by the respondent's colleagues. The result is given in table 14 .

Table 14

Direct and Indirect Downline Who Were Friends Or Relatives

\begin{tabular}{|l|c|c|c|}
\hline \multirow{2}{*}{$\begin{array}{l}\text { Relationship } \\
\text { Strength }\end{array}$} & \multicolumn{3}{|c|}{$\begin{array}{c}\text { Average Number of Direct and Indirect Downline Who were } \\
\text { friends and Relatives }\end{array}$} \\
\cline { 2 - 4 } & Direct Downline & Indirect Downline & Total \\
\hline Strong & 18 & 13 & 31 \\
\hline Weak & 3 & 6 & 9 \\
\hline Total & 21 & 19 & 40 \\
\hline
\end{tabular}

The table 14 indicates that the distributors having strong relationship strength was able to recruit 31 downline on an average under them who were relatives and friends. Of this, eighteen downline are direct downline and thirteen are indirect downline. At the same time it is obvious that distributors having weak relationship strength had less number of downline under them who were friends and relatives.

\section{vi) Pre-existing Relationship}

Respondents were asked to rate their relationship with their upline sponsor before they began using the company's products or working as a distributor. Responses are depicted in table 15.

The table reveals that $68 \%$ of respondents gave a score to 'acquaintance' or lower, $21 \%$ of these reported 'no previous contact' and $11 \%$ said they were 'close friends'. The opinion regarding the relationship has also given as a breakup according to length of experience. Of the $11 \%$ of respondents who considered themselves as close friends, $57 \%$ of them have an experience of two to five years. Thus, this measure was treated as a binary variable, in which a score less than or equal to 4 "acquaintance" was coded as 0 ("no 
Significance of Relationship in Multilevel Marketing and its effect on Business Outcome previous friendship") and a score greater than 4 was coded as 1 ("previously friends"). Thus it is concluded that $79 \%$ of the respondents who joined in the MLM system had previous relationship with their upline sponsors.

Table 15

Pre-Existing Relationship with Sponsor

\begin{tabular}{|l|c|c|c|c|}
\hline \multirow{2}{*}{ Length of Experience } & \multicolumn{4}{|c|}{ Pre-existing Relationship with Upline Sponsor } \\
\cline { 2 - 5 } & No previous contact & Acquaintance & Close friend & Total \\
\hline Less than 2 year & $67(52)$ & $329(79)$ & $8(12)$ & 404 \\
\hline Between 2-5 years & $48(38)$ & $77(18)$ & $39(57)$ & 164 \\
\hline More than 5 years & $13(10)$ & $12(3)$ & $21(31)$ & 46 \\
\hline \multicolumn{1}{|c|}{ Total } & $128(21)$ & $418(68)$ & $68(11)$ & 614 \\
\hline
\end{tabular}

Source: Survey Data

\section{Relationship and Business Outcome}

It is predicted that distributors' with strong feelings of relationship toward their business partners would produce better business outcomes than distributors with weak feelings of relationship. This hypothesis was tested by examining two different kinds of relationships: respondents' relationships with their upline sponsor and respondents' relationships with those in their downline.

The computation of statistics connected with the relationship between respondents' and their upline for hours of network management, sales and recruiting is shown in the table 16.

Table 16

Relationship of Respondents and Business Outcome

\begin{tabular}{|l|c|c|c|}
\hline \multirow{2}{*}{ Business Outcome } & \multicolumn{3}{|c|}{ Regression Results: Beta Coefficients } \\
\cline { 2 - 4 } & Beta Coefficient & $\boldsymbol{t}$ values & $\boldsymbol{p}$ values \\
\hline Network Management & 0.16 & 2.94 & $\mathrm{P}<.01$ \\
\hline Sales & 0.18 & 2.23 & $\mathrm{P}<.05$ \\
\hline Recruiting & 0.28 & 7.33 & $\mathrm{P}<.01$ \\
\hline
\end{tabular}

First, the hypothesis was supported for relationships between respondents and their downlines. It was a significant predictor of hours of network management $(\mathrm{B}=.16, \mathrm{t}=2.94, p<.01)$, sales $(\mathrm{B}=.18, \mathrm{t}=2.94, p<$ $.05)$ and recruiting $(\mathrm{B}=.0 .28, \mathrm{t}=7.33, p<.01)$. However it was not supported for upline-sponsor relationships as none of the relevant regression coefficients are significant.

\section{i) Training and Relationship with Sponsor}

However, this main effect of relationship was significantly moderated by training, and the data pattern suggests that relationships with upline sponsors have a positive effect on business outcomes, but only for relationships with relatively low instrumentality. The statistics relating to training and relationship is given it table 17. Training negatively moderated the effect of relationships with both the upline sponsor and downline distributors. The interaction between relationships with the upline sponsor and training was a significant, negative predictor of hours spent on selling $(\mathrm{B}=-.08, \mathrm{t}=2.02, p<.05)$, recruiting $(\mathrm{B}=-0.11, \mathrm{t}=2.06, p<.05)$ and network management $(\mathrm{B}=-0.13, \mathrm{t}=3.47, p<.01)$.

Table 17

Effect of Training on the Relationship With Sponsor

\begin{tabular}{|l|c|c|c|}
\hline \multirow{2}{*}{ Business Outcome } & \multicolumn{3}{|c|}{ Regression Results: Beta Coefficients } \\
\cline { 2 - 4 } & Beta Coefficient & $\boldsymbol{t}$ values & $\boldsymbol{p}$ values \\
\hline Network Management & -0.13 & 3.47 & $\mathrm{P}<.01$ \\
\hline Sales & $0 .-.08$ & 2.02 & $\mathrm{P}<.05$ \\
\hline Recruiting & -0.11 & 2.06 & $\mathrm{P}<.05$ \\
\hline
\end{tabular}

\section{ii) Training and Relationship with Downline}

The beta coefficient relating to interaction between downline relationships and training is given in table 18.

The beta coefficient relating to interaction between downline relationships and training was a significant negative predictor of hours spent on recruiting $(\mathrm{B}=-.16, \mathrm{t}=2.91, p<.01)$ and network management $(\mathrm{B}=-.41, \mathrm{t}=7.37, p<.01)$, as well as of sales $(\mathrm{B}=-.13, \mathrm{t}=2.39, p<.05)$. This interaction was also a marginally significant predictor of recruits $\mathrm{B}=-.09, \mathrm{t}=1.88, p<.10$. These results provide support for the general proposition that a conflict between relationship and the instrumentality emphasized by training can undermine business outcomes. 
Table 18

Effect of Training on the Relationship With Downline

\begin{tabular}{|l|c|c|c|}
\hline \multirow{2}{*}{ Business Outcome } & \multicolumn{3}{|c|}{ Regression Results: Beta Coefficients } \\
\cline { 2 - 4 } & Beta Coefficient & $\boldsymbol{t}$ values & $\boldsymbol{p}$ values \\
\hline Network Management & -0.41 & 7.37 & $\mathrm{P}<.01$ \\
\hline Sales & $0 .-.11$ & 2.39 & $\mathrm{P}<.05$ \\
\hline Recruits & -0.16 & 2.91 & $\mathrm{P}<.01$ \\
\hline
\end{tabular}

\section{iii) Training and Business Outcome}

The negative interactions are occurred because the training in network marketing could be particularly poor and that this could cause a decrease in commitment and productivity. Recognizing that good training should have a positive influence on commitment and productivity, researcher tested training's main effect on the dependent variables. The result is shown in table 19 .

Contrary to the above finding, training had a significant, positive main effect on hours spent on selling $(\mathrm{B}=.23$, $\mathrm{t}=3.59, p<.01)$, recruiting $(\mathrm{B}=.26, \mathrm{t}=5.05, p<.01)$, and network management $(\mathrm{B}=.29, \mathrm{t}=2.94, p<.01$.$) .$

\section{Table 19}

Effect of Training on Business Outcome

\begin{tabular}{|l|c|c|c|}
\hline \multirow{2}{*}{ Business Outcome } & \multicolumn{3}{|c|}{ Regression Results: Beta Coefficients } \\
\cline { 2 - 4 } & Beta Coefficient & $\boldsymbol{t}$ values & $\boldsymbol{p}$ values \\
\hline Network Management & 0.29 & 2.94 & $\mathrm{P}<.01$ \\
\hline Sales & 0.23 & 3.59 & $\mathrm{P}<.01$ \\
\hline Recruiting & 0.26 & 5.05 & $\mathrm{P}<.01$ \\
\hline
\end{tabular}

\section{Summary of Findings}

A summary of findings obtained from the analysis of data is given below:

1. Many of the respondents are joined under the influence of others especially from friends and relatives who used personal relationships to enrol new distributors. A majority of the respondents joined in the scheme simply due to the heavy pressure from others.

2. Most of the respondents had joined as a distributor as a result of continuous pressure from existing distributors. The remaining distributor were motivated by other reasons such as intention to use good quality products and of which only few of the respondents was taken up the multilevel marketing system as a means of employment.

3. Respondents contacted their friends, relatives and colleagues for the purpose of enrolling them as distributors of MLM. The distributors who are having less experience mainly contacted their relatives for the purpose of enrolment. On the other hand, distributors having more experience approached their colleagues to expand the network.

4. Majority of respondents have a strong relationship with their sponsors. This again reveals the fact that the very foundation of MLM and the management of network is built up on relationships.

5. Distributor having strong relationship strength was able to recruit more downline under them who were relatives and friends. At the same time it is obvious that distributor having weak relationship strength had less number of downline under them who were friends and relatives.

6. The study reveals that most of the respondents had a relationship of 'acquaintance' or lower and very few respondents were 'close friends'.

\section{Recommendations}

Based on the findings of the study, the researcher would like to give the following recommendations suggestions to strengthen the MLM business and to avoid its present pitfalls.

- In order to build up a clean and healthy industry image, the government can legalise the business by enacting suitable law in the country to regulate the operation of multilevel marketing companies.

- The MLM companies should be brought under the umbrella of consumer protection legislations.

- The government can impose strict regulations on direct sellers, including an upfront investment and a security deposit to protect consumers.

- Many of the respondents are joined under the influence of others especially from friends and relatives who used personal relationships to enrol new distributors. This is quite unethical using personal relationships for making money. Therefore it is highly necessary to the prospects to clearly understand the pros and cons of the system before he is actually enrolled.

- Most of the respondents are new recruits. Hence MLM companies should take steps to design compensation plan characterised by relative horizontal equality in which total remuneration including salary, 

commissions, and bonuses is shared at least somewhat fairly among all participants, based on their value and contributions to the organisation.

- Government should take sufficient steps to watch the activities of MLM companies. For this purpose regional nodal offices can be set up which should be headed by nodal officers.

\section{Conclusion}

Every industry is undergoing dramatic changes and this is affecting the future of every country. Technology is driving the lives of mankind as they struggles to live with accelerated rate of change. Just has it happened between the agricultural and industrial revolutions, in the new information revolution, there seems to be a massive social dislocation with rich getting richer and poor become poorer. Direct sales have become so popular because it offers everyone the chance of becoming a successful self employed opportunity with the freedom to win and little lose.

As it is likely to happen in every business MLM industry is also overwhelmed with unscrupulous elements trying to exploit the situation in an undesirable way. Many of those who quit are so convinced that they personally 'failed' they are told by the organizers that everyone can succeed, so if they do fail it is only their own fault that they do not complain about the scheme to the government authorities or even warn friends about not also joining. Virtually the only people buying the goods are the schemes own sales representatives and their friends or family. They buy goods, not on the basis of their value or need for them, but on the basis of false promises of income.

The greatest challenge believes in the positive future of direct sales enough to create the desire and commitment to go into massive action. Instead of devoting their time in recruiting efforts there is a need to enter into the real business of selling the products. Otherwise it will simply become a pyramid scheme and consequently the faith of the general public in MLM business will be lost. The whole business will be treated as unethical and the public image will seriously be hampered. In direct sales millions will join and many will leave as their lives and needs change.

Findings of this study would help policy makers and managers of companies as well as practitioners to formulate strategies and program to overcome turnover problem among MLM distributors as well as to ensure efficiency, effectiveness and high productivity in organization.

\section{References}

[1] Berry, R. (1997) "Direct Selling - from Door to Door to Network Marketing”, Butterworth Heinemann, Oxford. P.21.

[2] Carmichael, Allen (1993),Network and Multi-Level Marketing Reading,UK: Concept.

[3] Clothier, Peter (1994),Multi-Level Marketing London: Kogan Page. Conflict,” Journal of Applied Psychology 76 (4), p.560 -68.

[4] Poe,Richard (1995),Wave 3: The New Era in Network Marketing Rocklin,CA:Prima.

[5] Lan,Pei-Chia (2002),"Networking Capitalism:Network Construction and Control Effects in Direct Selling," Sociological Quarterly Vol.43 (2), p.165-184.

[6] Pratt, Michael G.(2000),"The Good, the Bad, and the Ambivalent: Managing Identification Among Amway Distributors," Administrative Science Quarterly Vol.45 (3), p. $456-493$.

[7] Grayson,Kent (1996), “Examining the Embedded Markets of Network Marketing Organizations," in Networks in Marketing, Dawn Iacobucci,ed.Thousand Oaks,CA:Sage Publications, p. $325-41$.

[8] Merrilees,Bill and Dale Miller (1999), "Direct Selling in the West and East:The Relative Roles of Product and Relationship (Guanxi) Drivers,”Journal of Business Research Vol.45 (3), p.267 -73.

[9] Tan,Cheryl Lu-Lien and Brian Steinberg (2007), "Penney 's Updated Image, The Sequel,” The Wall Street Journal (February 13).

[10] Broker (2005), “Getting Leads from Newbie Realtors,” 7 (February -March), p.55.

[11] Huisken, Brad (2005),“Top 10 Ways a Salesperson Can Increase Sales,”Jewelers' Circular Keystone Vol.176 (June), p.15.

[12] Meagher,Lisa (2006), “Gift Incentives for Customers Bring in Business,”Community Banker Vol.15 (May), p.24.

[13] Bulik,Beth Snyder (2006), “Want a Free iPod?Just Click Here,” Advertising Age (March 6), p.3.

[14] Mitchell,Alan (2003), “Trust in Your Customers to Handle the Marketing Flow,"Marketing Week (May 29), p.30. 